\title{
Microheterogeneity and Some Properties of the Major Glycoprotein Fraction Isolated from Bovine Milk Fat Globule Membrane after Delipidation
}

\author{
Makoto ShImizu, Choemon KanNo and Kunio Yamauchi \\ Department of Agricultural Chemistry, The University of Tokyo, \\ Bunkyo-ku, Tokyo 113, Japan \\ Received November 22, 1977
}

\begin{abstract}
A major glycoprotein, $\mathrm{CB}-7+8$ component, was selectively precipitated by dialyzing the fraction extracted with $1 \mathrm{M} \mathrm{KCl}$ from the delipidated milk fat globule membrane against deionized water. The CB-7+8 contained $4.16 \%$ hexoses, $2.05 \%$ hexosamines and $2.08 \%$ sialic acid.

The CB-7 +8 component was observed to be able to associate with the constituent polypeptides of the soluble glycoprotein, PAS-I VII and CB-III, and to form a soluble complex.

The CB-7+8 component which gave an apparently asymmetrical monopeak on sodium dodecyl sulfate-polyacrylamide gel electrophoresis showed remarkable heterogeneity on isoelectric focusing, and six major bands of pl ranging from 5.9 to 6.8 were observed. The results of digestion of $\mathrm{CB}-7+8$ with neuraminidase suggested that this heterogeneity was due to the microheterogeneity of oligosaccharide chains having a variable number of sialic acid residues.
\end{abstract}

The milk fat globule membrane (MFGM) is derived from mammary secretory cell membranes..$^{1 \sim 31}$

The presence of many protein components was revealed in MFGM by sodium dodecyl sulfate-polyacrylamide gel electrophoresis (SDS-PAGE). ${ }^{4 \sim 8)}$ However, purification and characterization of the individual proteins had not been performed for a long time with the exception of some glycoproteins which form a soluble complex after delipidation of MFGM. ${ }^{9 \sim 14\}}$ Recently, Cawston et al. $^{15)}$ and Basch et al. ${ }^{16)}$ isolated major proteins of MFGM by gel chromatography in the presence of SDS. However, the purity and homogeneity of the proteins they isolated appear to be questionable. Furthermore, physicochemical properties of the individual proteins are still unknown.

We have found that a major glycoprotein fraction can be extracted from delipidated MFGM with $1 \mathrm{M} \mathrm{KCl}$ and selectively precipitated by following dialysis against water. ${ }^{14}$ ? It is observed that this glycoprotein fraction apparently consists of 2 proteins (CB- $7+8$ in the present study) having slightly different electrophoretic mobilities on SDS-PAGE. ${ }^{14}$ However, the cause of heterogeneity of this fraction is unknown. In this paper, we report some chemical and physical properties of the glycoprotein fraction, $\mathrm{CB}-7+8$, obtained by the procedure in which SDS is not used.

\section{MATERIALS AND METHODS}

\section{Preparation of apoprotein fractions of MFGM}

MFGM was prepared by the previously described procedure. ${ }^{12)}$ MFGM suspended in water was freezedried and stored at $-20^{\circ} \mathrm{C}$ in $\mathrm{N}_{2}$ gas. Apoprotein fractions of MFGM were prepared by the MCF-2 procedure described in the previous paper ${ }^{14)}$ and as summarized in Fig. 1.

Five grams of freeze-dried MFGM were suspended in $100 \mathrm{ml}$ of cold methanol: chloroform mixture $(1: 2$, $\mathrm{v} / \mathrm{v})$, and the suspension was stirred for $30 \mathrm{~min}$ at $4^{\circ} \mathrm{C}$ and filtered through No. $5 \mathrm{~A}$ filter paper under vacuum suction at $4^{\circ} \mathrm{C}$. The precipitate was resuspended in the solvent mixture and treated in the same way. After filtration, the precipitate was washed with cold acetone for $15 \mathrm{~min}$ and suspended in $150 \mathrm{ml}$ of water. The residual organic solvent in the suspension was removed with a rotary evaporator below $40^{\circ} \mathrm{C}$. To this suspension was added solid $\mathrm{KCl}$ to achieve $1 \mathrm{M}$ concentration, and the suspension was stirred at $4^{\circ} \mathrm{C}$ for $2 \mathrm{hr}$ and centrifuged at $25,000 \times g$ for $1 \mathrm{hr}$ at $4^{\circ} \mathrm{C}$. The soluble 
Freeze-dried MFGM

Added $200 \mathrm{ml}$ of methanolchloroform mixture $(1: 2, \mathrm{v} / \mathrm{v})$ per gram of solid, stirred at $4^{\circ} \mathrm{C}$, and filtered (repeated twice).

Residue

Washed with acetone, and the residual solvent evaporated.

Delipidated MFGM

Extracted with $1 \mathrm{M} \mathrm{KCl}$, and centrifuged at $25,000 \times g$ for $1 \mathrm{hr}$.

Soluble fraction (sup-1) Insoluble fraction (ppt-1)

Dialyzed against water, and centrifuged at $25,000 \times g$ for $1 \mathrm{hr}$.

Soluble fraction (sup-2) Insoluble fraction Dissolved in $1 \mathrm{M}$ $\mathrm{KCl}$, dialyzed against water, and centrifuged at $25,000 \times g$ for $1 \mathrm{hr}$.

\section{Soluble fraction (sup-3) Insoluble fraction (ppt-2)}

FIG. 1. Preparation of Apoprotein Fractions of MFGM by Extracting Delipidated MFGM with $1 \mathrm{M}$ $\mathrm{KCl}$.

fraction (sup-1) was dialyzed against water at $4^{\circ} \mathrm{C}$. During dialysis, insoluble materials were formed. They were collected by centrifugation at $25,000 \times g$ at $4^{\circ} \mathrm{C}$ after complete removal of salt by dialysis. In order to remove contaminated soluble components, the insoluble fraction was redispersed in $1 \mathrm{M} \mathrm{KCl}$, dialyzed against water and collected by centrifugation (ppt-2). These apoprotein fractions were freezedried and subjected to analyses.

Gel fitration. A column $(1.3 \times 80 \mathrm{~cm})$ was packed with Sephacryls 200 Superfine (Pharmacia Chem. Co., Ltd.) and was equilibrated with $0.05 \mathrm{M}$ phosphate buffer, pH 8.0 , containing $1 \mathrm{M} \mathrm{KCl}$ and $0.02 \%$ sodium azide at $4 . \mathrm{C}$. Fifteen milligrams of ppt-2 dissolved in $2 \mathrm{ml}$ of the above buffer was applied to the column and eluted with the same buffer. Absorbance of the eluate was determined at $280 \mathrm{~nm}$.

SDS-polyacrylamide gel electrophoresis (SDS$P A G E)$. SDS-PAGE was carried out by the method of Weber and Osborn ${ }^{17}$ at $10 \%$ acrylamide gel concentration. Gels were stained with coomassie blue R-250 (CB) and periodic acid-Schiff (PAS), and scanned with an ISCO Model UA-5 Absorbance Spectrometer with a linear transport system. The bands detected by CB-staining were designated as CB-1 to 13 and CB-I to III, and those by PAS-staining, as PAS-1 to 7 and PAS-I to VII. Roman numerals are used for the polypeptides of the soluble glycoprotein and Arabic numerals, for the major polypeptides of the total MFGM, as described in the previous paper. ${ }^{83}$
Isoelectric focusing. Gel solution containing 5.0\% acrylamide, $0.25 \%$ methylene bisacrylamide, $2 \%$ Ampholine (pH 3.5 10, LKB Instruments), $2 \sim 5 \mathrm{M}$ urea, $0.25 \%$ Triton $\mathrm{X}-100,0.0005 \%$ riboflavin, $0.0625 \%$ tetramethylethylenediamine (TEMED) and $0.0625 \%$ ammonium persulfate was prepared. After exposure to yacuum suction to remove air bubbles, the gel solution was poured into glass columns $(5 \times 100$ $\mathrm{mm}$ ) and polymerized under a fluorescent lump.

One milligram of protein sample was dissolved in $2 \mathrm{ml}$ of $8 \mathrm{M}$ urea containing $0.5 \%$ Triton $\mathrm{X}-100$ and $1 \%$ 2-mercaptoethanol, and solubilized by heating for $1 \sim$ $2 \mathrm{~min}$ in a boiling water bath. The protein solution was then mixed with an equal volume of $60 \%$ glycerol containing 4\% Ampholine ( $\mathrm{pH} 3.5 \sim 10$ ). A proteinAmpholine mixture $(50 \mu \mathrm{l})$ was applied to a gel column. As a protect solution, $50 \mu 1$ of $15 \%$ glycerol containing $2 \%$ Ampholine (pH 3.5 10) and $0.8 \%$ glutamic acid (pH 4.7) was gently loaded on the sample layer to avoid disruption of the interface. ${ }^{18)}$

The upper reservoir (anode) was filled with $0.02 \mathrm{M}$ $\mathrm{H}_{3} \mathrm{PO}_{4}$ and the lower (cathode) with $1 \mathrm{M} \mathrm{NaOH}$. Electrofocusing was carried out at $4^{\circ} \mathrm{C}$ under a constant current of $1 \mathrm{~mA}$ per gel column until the voltage was raised to $200 \mathrm{~V}$. The voltage was then maintained for $4 \sim 6 \mathrm{hr}$ until the current dropped passively and reached a constant value $(0.1 \sim 0.3 \mathrm{~mA}$ per column). After electrofocusing, unfixed gels were sliced into 27 sections $(3 \mathrm{~mm}$ width), which were suspended in a small amount of deionized water overnight at $4^{\circ} \mathrm{C}$. The $\mathrm{pH}$ was measured with a combined microelectrode at $4^{\circ} \mathrm{C}$.

Protein-staining of focused gels was performed in accordance with the procedure of Reisner et al., ${ }^{183}$ and carbohydrate-staining was performed by the PASprocedure ${ }^{20}$ after washing the gels in $40 \%$ methanol$10 \%$ acetic acid for two days to remove Ampholines. The stained gels were scanned at $546 \mathrm{~nm}$ or $510 \mathrm{~nm}$ with an ISCO Absorbance Spectrometer Model UA-5.

Chemical analysis. Amino acid analysis was performed on a Nippon Densi JLC-6AH amino acid analyzer. Samples of protein were hydrolyzed in $6 \mathrm{~N}$ $\mathrm{HCl}$ at $110^{\circ} \mathrm{C}$ for $20 \mathrm{hr}$ in evacuated sealed Pyrex tubes.

Hexoses were determined by the method of Dubois et al. ${ }^{21)}$ with a mixture of galactose and mannose $(1: 1)$ as standard. Hexosamines were determined by the method of Stewart-Tull ${ }^{22}$ ) after hydrolysis with $2 \mathrm{~N}$ $\mathrm{HCl}$ for $6 \mathrm{hr}$ at $100^{\circ} \mathrm{C}$. A mixture of $\mathrm{N}$-acetylglucosamine- $\mathrm{HCl}$ and $\mathrm{N}$-acetylgalactosamine- $\mathrm{HCl}(1: 1)$ was used as standard. Sialic acid was determined by the method of Warren ${ }^{23)}$ after hydrolysis with $0.1 \mathrm{~N} \mathrm{H}_{2} \mathrm{SO}_{4}$ for $1 \mathrm{hr}$ at $80^{\circ} \mathrm{C}$, with $\mathrm{N}$-acetylneuraminic acid used as standard.

Neuraminidase digestion. One milligram of protein sample was dispersed in $0.5 \mathrm{ml}$ of $0.1 \mathrm{M}$ acetate buffer, pH 5.0. An equal volume of the same buffer containing $200 \mu \mathrm{g}$ of neuraminidase (from Cl. perfringens, 
Sigma, 0.22 units $/ \mathrm{mg}$ ) was added, followed by incubation at $37^{\circ} \mathrm{C}$ for $3 \mathrm{hr}$ with stirring, after which the mixture was dialyzed against water at $4^{\circ} \mathrm{C}$. The desialilated ppt- 2 fraction was precipitated by centrifuging at $25,000 \mathrm{~g}$ for $30 \mathrm{~min}$ and freeze-dried.

\section{RESULTS}

Isolation and compositions of $C B-7+8$ fraction

By extracting delipidated MFGM with $1 \mathrm{M}$ $\mathrm{KCl}, 15 \sim 20 \%$ of total protein was solubilized (sup-1). A part of this solubilized protein precipitated when the $\mathrm{KCl}$ concentration was lowered by dialysis against deionized water (ppt-2).

On SDS-PAGE, it was shown that $1 \mathrm{~m}$ $\mathrm{KCl}$-extractable, water-soluble fractions (sup2 and 3) contained CB-7+8 in company with relatively low molecular weight polypeptides such as CB-12, 13 and PAS-II $\sim$ VII which are the constituent polypeptides of the soluble glycoprotein $^{8,14}$ (Fig. 2-A and B). On the other hand, $1 \mathrm{M}$ KCl-extractable, water-insoluble fraction (ppt-2) was found to be mostly composed of CB-7+8 (Fig. 2-C). The

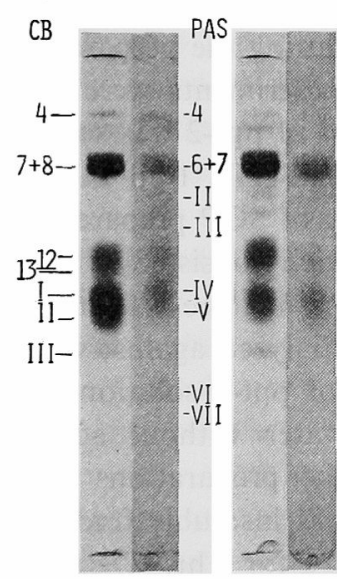

(A)

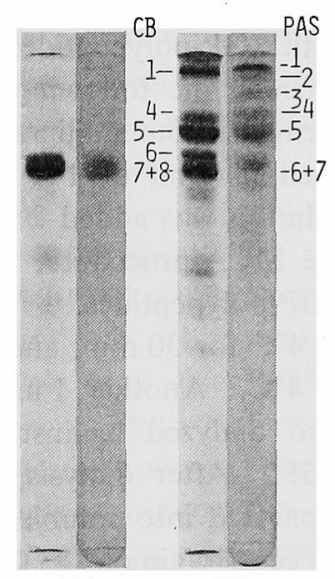

(C)
(D)
Fig. 2. SDS-PAGE Patterns of Apoprotein Fractions of MFGM.

A) $1 \mathrm{M} \mathrm{KCl}$-soluble, water-soluble fraction (sup-2), B) $1 \mathrm{M} \mathrm{KCl}$-soluble, water-soluble fraction (sup-3), C) $1 \mathrm{M} \mathrm{KCl}$-soluble, water-insoluble fraction (ppt-2), D) $1 \mathrm{M} \mathrm{KCl}$-insoluble fraction (ppt-1).

Gels were stained with coomassie blue R-250 for protein (left of each pair) and with periodic acidSchiff reagent for carbohydrate (right of each pair). percentage of $\mathrm{CB}-7+8$ (PAS- $6+7$ ) in this fraction calculated from the scanning profiles of SDS-PAGE patterns was 84 for CB-staining or 80 for PAS-staining. Other major proteins and glycoproteins of MFGM were not extracted with $1 \mathrm{M} \mathrm{KCl}$ and were recovered in the residue fraction (ppt-1, Fig. 2-D).

The ppt- 2 fraction was fractionated into two peaks on gel filtration as shown in Fig. 3. The fractions corresponding to the first peak (Fraction I) and the second peak (Fraction II) were separately collected, dialyzed against deionized water and freeze-dried. SDS-PAGE study indicated that Fraction II contained CB- $7+8$ of high purity $(93 \%$ for CB-staining and $91 \%$ for PAS-staining), while Fraction I still contained other minor proteins in addition to $\mathrm{CB}-7+8$, suggesting they interacted even in $1 \mathrm{M} \mathrm{KCl}$ (Fig. 4). However, the yield of Fraction II was very low.

The amino acid and carbohydrate compositions of the ppt- 2 fraction were determined and are shown in Tables I and II, respectively. The contents of glutamic acid, aspartic acid, serine and leucine are high, while those of histidine, methionine, cystine, isoleucine, tyrosine and phenylalanine are low. Cawston et $a l^{15)}$ and Basch et al. ${ }^{16)}$ isolated $\mathrm{CB}-7+8$ (designated as protein $\mathrm{V}$ by Cawston et $a l^{15}{ }^{15}$

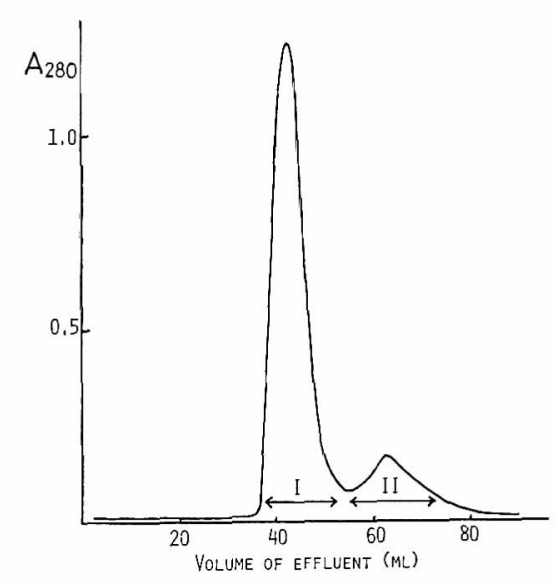

FIG. 3. Typical Gel Filtration Pattern of CB- $7+8$ Fraction (Ppt 2) on Sephacryls 200 Superfine.

Proteins $(15 \mathrm{mg}$ ) were dissolved and eluted with $0.05 \mathrm{M}$ phosphate buffer, $\mathrm{pH} 8.0$, containing $1 \mathrm{M} \mathrm{KCl}$. 


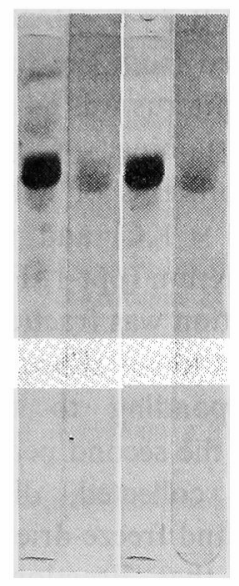

(A) (B)

Fig. 4. SDS-PAGE Patterns of Proteins Fractionated by Gel Filtration on Sephacryls 200.

A) Fraction I, B) Fraction II shown in Fig. 3.

Gels were stained with coomassie blue R-250 for protein (left of each pair) and with periodic acidSchiff reagent for carbohydrate (right of each pair).

Table I. Amino Acid Composition of CB-7+8 Fraction (ppt-2)

Values are expressed in mole \% of total amino acids.

\begin{tabular}{lc}
\hline \multicolumn{1}{c}{ Amino acid } & CB-7 +8 fraction \\
\hline Lysine & 5.9 \\
Histidine & 2.4 \\
Arginine & 4.3 \\
Aspartic acid & 9.0 \\
Glutamic acid & 12.1 \\
Threonine & 7.1 \\
Serine & 9.4 \\
Proline & 7.2 \\
Glycine & 7.3 \\
Alanine & 6.5 \\
1/2 Cystine & 0 \\
Valine & 5.9 \\
Methionine & 3.3 \\
Isoleucine & 3.9 \\
Leucine & 9.1 \\
Tyrosine & 3.0 \\
Phenylalanine & 3.7 \\
Tryptophan & Not determined \\
\hline
\end{tabular}

and as glycoprotein B by Basch et al. ${ }^{16)}$ ) by gel filtration in the presence of SDS, and analyzed it. The amino acid compostion of the ppt-2 fraction was in good agreement with their results except that the contents of cystine, isoleucine and phenylalanine were lower and those of serine, proline and methionine were
Table II. Carbohydrate Composition of CB-7+8 FraCTION (ppt-2)

Values are expressed in $\mathrm{mg} / 100 \mathrm{mg}$ protein.

\begin{tabular}{lc}
\hline Carbohydrate & CB-7+8 fraction \\
\hline Hexoses & 4.16 \\
Hexosamines & 2.05 \\
Sialic acid & 2.08 \\
Total & 8.29 \\
\hline
\end{tabular}

slightly higher in our results. The total carbohydrate content was $8.3 \%$ in our study, and the sialic acid content of our sample was markedly lower than that reported by Basch et al. ${ }^{16)}$

Interaction of $C B-7+8$ with constituent polypeptides of the soluble glycoprotein

Although most of CB-7+8 became insoluble after dialysis against water, a part of $\mathrm{CB}-7+8$ remained in the soluble fractions (sup-2 and 3). It was, therefore, supposed that $\mathrm{CB}-7+8$ in a soluble form was interacting with the common constituent polypeptides of the soluble glycoprotein (SGP), such as PASI $\sim$ VII and CB-III, ${ }^{8)}$ which are designated as SGP-polypeptides in this paper.

To make clear whether CB- $7+8$ interacts with SGP-polypeptides during the preparation process, the following experiments were performed. Four milligrams of ppt-2 was solubilized in $2 \mathrm{ml}$ of $1 \mathrm{M} \mathrm{KCl}$. To $1 \mathrm{ml}$ of this solution was added $2 \mathrm{mg}$ of SGP prepared by the MCA-procedure, which consisted of only SGP-polypeptides. ${ }^{14)}$ The mixture was stirred at $4^{\circ} \mathrm{C}$ for $30 \mathrm{~min}$, and dialyzed against water at $4^{\circ} \mathrm{C}$. Another $1 \mathrm{ml}$ of ppt-2 solution was also dialyzed against water without adding SGP. After dialysis, the preparations were separated into soluble and insoluble fractions by centrifuging at $25,000 \mathrm{~g}$ for $1 \mathrm{hr}$. Distribution of $\mathrm{CB}-7+8$ was then investigated by SDS-PAGE. The results are shown in Fig. 5. In the presence of SGP-polypeptides a part of $\mathrm{CB}-7+8$ (PAS-6+7) remained in the soluble fraction, while in their absence all of $\mathrm{CB}-7+8$ (PAS-6+7) became insoluble. The results indicate that $\mathrm{CB}-7+8$ (PAS-6+7) can associate with SGP-polypeptides in $1 \mathrm{M} \mathrm{KCl}$ or during the dialysis step. Calculated from densito- 


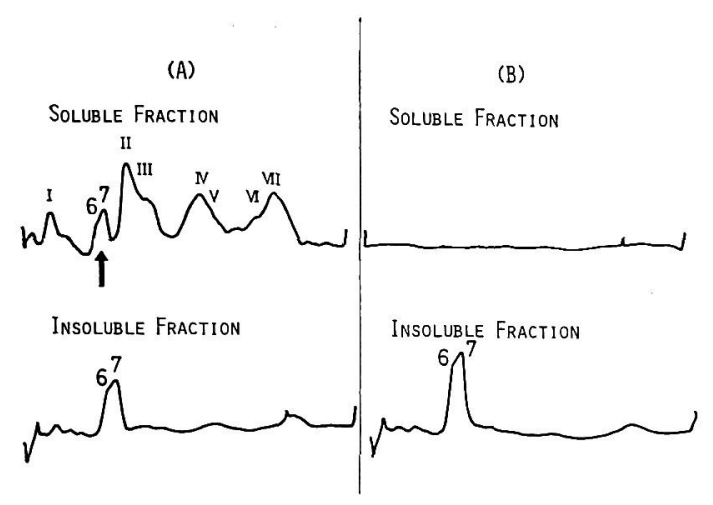

FIG. 5. Interaction of CB-7+8 (PAS-6+7) with the Constituent Polypeptides of the Soluble Glycoprotein Shown by SDS-PAGE.

A) In the presence of the constituent polypeptides of the soluble glycoprotein. B) In the absence of the constituent polypeptides of the soluble glycoprotein. PAS- $6+7$ partly remained in the soluble fraction when the soluble glycoprotein coexisted in the solution, as indicated by the arrow. The soluble glycoprotein was prepared by the MCA-procedure. ${ }^{1+)}$ Gels were stained with PAS and scanned at $546 \mathrm{~nm}$.

metric scanning profiles, the ratio of $\mathrm{CB}-7+8$ (PAS-6+7) to SGP-polypeptides in the soluble fraction was one-third to one-fourth under the experimental conditions used herein. The results also support our previous supposition that the medium for extraction of soluble apoproteins affected the molecular properties of the resultant apoprotein complexes. ${ }^{14)}$

\section{Heterogeneity of $C B-7+8$ fraction}

On SDS-PAGE, CB-7 and 8 show very similar mobilities and are only detected as an asymmetrical mono peak or a peak with a shoulder reflecting their nearly equal molecular sizes. Both proteins also showed similar behaviors in the extraction experiments reported previously ${ }^{6,14,24}$ and in this paper. Because of these similar properties of $\mathrm{CB}-7$ and 8 , it is still unknown whether the components corresponding to the band of $\mathrm{CB}-7$ and 8 consist of only two polypeptides. To obtain further information about the heterogeneity of $\mathrm{CB}-7+8$ fraction, we introduced an isoelectric focusing technique. Triton $X_{-}$ 100 and urea were allowed to coexist in the gel medium to maintain solubility of proteins and

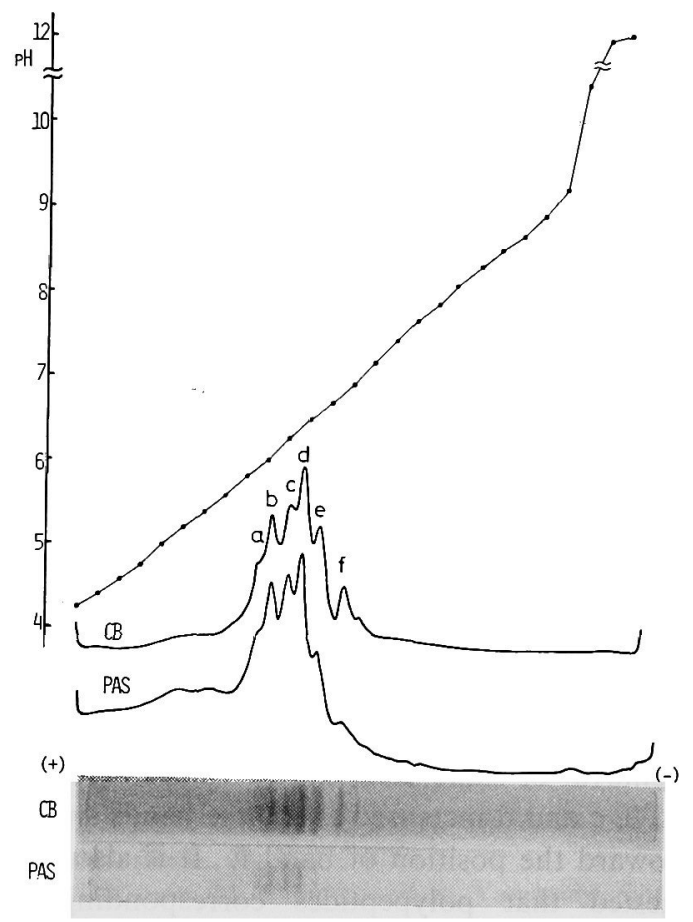

FIG. 6. Heterogeneity of CB-7+8 Fraction (ppt-2) on Isoelectric Focusing. Focusing was performed in $2 \%$ Ampholine, $5 \mathrm{~m}$ urea and $0.25 \%$ Triton $\mathrm{X}-100$ at $4{ }^{\circ} \mathrm{C}$ for $6 \mathrm{hr}$. Protein and carbohydrate were stained with coomassie blue G-250 and periodic acid-Schiff, respectively. Stained gels were scanned at $546 \mathrm{~nm}$.

to prevent intermolecular association among polypeptides. ${ }^{25}$,

The ppt-2 fraction showed remarkable heterogeneity on isoelectric focusing gels, and about six major bands were observed upon staining with PAS and CB, as shown in Fig. 6. The isoelectric $\mathrm{pH}$ range of the bands was $5.9 \sim 6.8$. The pIs of bands $a, b, c, d$, e and $f$ indicated in the Figure were 5.9, 6.1, 6.3, 6.4, 6.6 and 6.8, respectively. Sephacryls 200Fraction II also showed an identical pattern in respect to bands $a \sim f$ on isoelectric focusing gels.

Each of the protein fractions extracted from isoelectric focusing gel sections corresponding to $\mathrm{pH}$ ranges $5.7 \sim 5.9,5.9 \sim 6.1,6.1 \sim 6.35$, $6.35 \sim 6.6$ and $6.6 \sim 6.8$ was dialyzed against $40 \%$ methanol to remove Ampholines and Triton X-100, and subjected to SDS-PAGE. All of these extracted protein fractions gave a 
relatively broad band of the same mobility as the original preparation of $\mathrm{CB}-7+8$ on SDSPAGE. From these results, it was concluded that the heterogeneous isoelectric focusing pattern truely reflected the heterogeneity of CB- $7+8$ in respect to the electric charge.

It is considered that the content of sialic acid may contribute to such heterogeneity observed by isoelectric focusing. In practice, removal of sialic acid by neuraminidase digestion caused striking changes in isoelectric focusing pattern as seen in Fig. 7. Although there were observed six bands with $\mathrm{pI}$ values identical to those of intact $\mathrm{CB}-7+8$, their quantitative ratio was quite different. The intensities of bands $a, b, c$ and $d$ decreased significantly, while that of band $f$ remarkably increased. The results suggested that, upon removal of sialic acid, the pI values of bands $a, b, c$ and $d$ increased and these bands shifted toward the position of band $\mathrm{f}$. It is also suggested that polypeptides corresponding to bands a, b, c, d, e and $f$ have basically the same core structure but contain different levels of sialic acid residue. Band $f$ seems to contain no sialic acid residue. The incomplete shift of

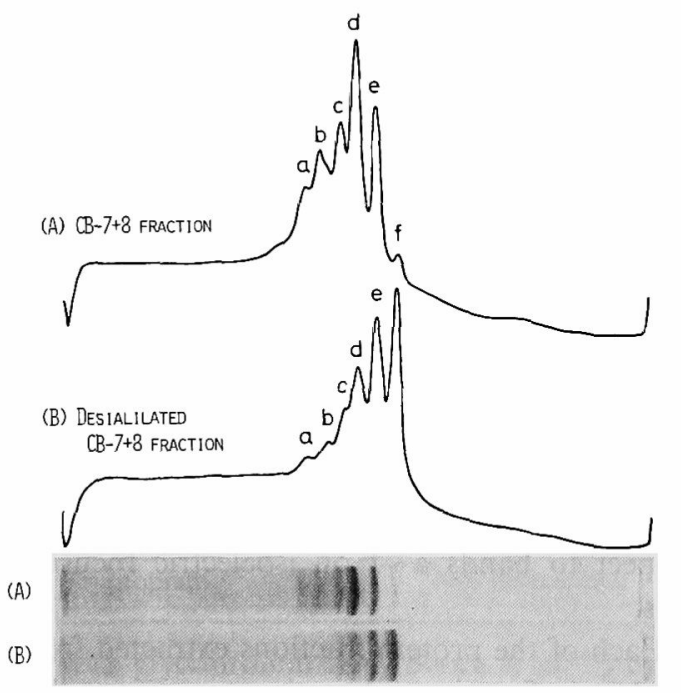

(t)

FIG. 7. Isoelectric Focusing Patterns of $\mathrm{CB}-7+8$ Fraction (ppt-2) before and after Digestion with Neuraminidase.

Gels were stained with coomassie blue G-250 and scanned at $546 \mathrm{~nm}$. bands $\mathrm{a} \sim \mathrm{e}$ into band $\mathrm{f}$ is likely to be due to incomplete digestion, since digestion was performed in the state of suspension of CB$7+8$ fraction which was insoluble in the incubation medium. The amount of sialic acid released under the experimental conditions used herein was $77 \%$. The broadness of the band of desialilated CB- $7+8$ on SDS-PAGE was not improved. This also may, at least partly, be due to the incomplete digestion.

\section{DISCUSSION}

In the present paper, we isolated $\mathrm{CB}-7+8$ which had been considered the major peripheral glycoproteins of MFGM, ${ }^{6,24}$ and investigated them with regard to two points; microheterogeneity and interactive property with the soluble glycoprotein fraction.

CB- $7+8$ was found to be selectively precipitated by dialyzing the $\mathrm{KCl}$-extract against deionized water. Although contamination of a small amount of relatively low molecular weight glycopeptides could not be excluded, CB- $7+8$ could be obtained in fairly high purity (ppt-2) by this method. In addition, a more purified fraction of $\mathrm{CB}-7+8$ could be obtained (Fraction II) by gel filtration in the presence of $1 \mathrm{M} \mathrm{KCl}$, but this fraction was too low in yield to analyze. Ppt-2 was used for chemical analyses. The differences in amino acid and especially carbohydrate composition between the present results and the previously reported values ${ }^{15,16)}$ might be dependent on the purity of the protein fractions subjected to analyses.

It was indicated that $\mathrm{CB}-7+8$ interacted with SGP-polypeptides in $1 \mathrm{M} \mathrm{KCl}$ and during dialysis step against water. Furthermore, judging from the fact that the interaction was observed even in the presence of $1 \mathrm{M} \mathrm{KCl}$ (Figs. 3, 4), there seemed to be some nonionic and irreversible bondings between the polypeptides. The inclusion of $\mathrm{CB}-7+8$ polypeptides in the soluble fraction (sup-2 and 3 ) is likely to be due to such interactive property of these polypeptides.

The heterogeneity of $\mathrm{CB}-7+8$ fraction was 
clearly observed by isoelectric focusing. It had been considered that the protein fraction corresponding to $\mathrm{CB}-7+8$ contained two proteins nearly equal in molecular weight but slightly different in electrophoretic mobility. $^{5,6,8,15)}$ Mather and Keenan ${ }^{6)}$ estimated the molecular weights of these two proteins to be 43,500 and 48,000 , and we estimated them to be 55,000 and 59,000 on SDS-PAGE. ${ }^{8}$ However, the present results indicated that this fraction consisted not only of two polypeptides but of at least six polypeptides with different electric charges. Cawston et al. ${ }^{15)}$ found the presence of another protein which had a similar electrophoretic mobility to that of CB-7 +8 (protein $\mathrm{V}$ in their report) but showed a different property on hydroxylapatite chromatography. This heterogeneity might relate to that shown in our present results. It is well known that there are many examples of heterogeneity of membrane glycoproteins. Such heterogeneity is generally attributed to microheterogeneity which represents variation in the carbohydrate groups of glycoprotein produced by partial substitution of sugar residues on basically the same core structure. ${ }^{26}$, Our results suggested that the heterogeneity of $\mathrm{CB}-7+8$ was due to the variable number of sialic acid residues.

It is probable that the heterogeneity of $\mathrm{CB}-7$ +8 component is due to microheterogeneity generated by post-synthetic modification of a biosynthetically homogeneous protein. However, there still is a possibility that the heterogeneity is also caused by the presence of multiple polypeptides having different primary structures.

No explanation was given in the present study as to the relationship between the heterogeneity of the $\mathrm{CB}-7+8$ fraction shown in SDS-PAGE (Fig. 2) and that shown in isoelectric focusing (Fig. 6). Further studies are needed to obtain a more definite conclusion on these points.

This work was partly supported by a Grant from the Ministry of Education, the Government of Japan (Grant No. 247112).

\section{REFERENCES}

1) J. R. Brunner, "Fundamentals of Dairy Chem- istry," 2nd ed., ed. by B. H. Webb, A. H. Johnson and J. A. Alford, the Avi Pub. Co., Ine., Westport, Connecticut, 1974, p. 474.

2) S. Patton and T. W. Keenan, Biochim. Biophys. Acta, 415, 273 (1975).

3) M. Anderson and T. E. Cawston, J. Dairy Res., 42, 459 (1975).

4) D. Kobylka and K. L. Carraway, Biochim. Biophys. Acta, 288, 282 (1972).

5) M. Anderson, T. Cawston and G. C. Cheeseman, Biochem. J., 139, 653 (1974).

6) I. H. Mather and T. W. Keenan, J. Membrane Biol., 21, 65 (1975).

7) M. E. Mangino and J. R. Brunner, J. Dairy Sci., 58, 313 (1975).

8) M. Shimizu, C. Kanno and K. Yamauchi, Agric. Biol. Chem., 40, 1711 (1976).

9) C. T. Herald and J. R. Brunner, J. Dairy Sci., 40, 948 (1957).

10) R. H. Jackson, E. J. Coulson and W. R. Clark, Arch. Biochem. Biophys., 97, 373 (1962).

11) F. C. Swope, K. C. Rhee and J. R. Brunner, Milchwissenshaft, 23, 744 (1968).

12) C. Kanno, M. Shimizu and K. Yamauchi, Agric. Biol. Chem., 39, 1845 (1975).

13) C. Kanno, M. Shimizu and K. Yamauchi, ibid., 41, 83 (1977).

14) K. Yamauchi, M. Shimizu and C. Kanno, $J$. Dairy Sci., in press.

15) T. E. Cawston, M. Anderson and G. C. Cheeseman, ibid., 43, 401 (1976).

16) J. J. Basch, H. M. Farrell, Jr. and R. Greenberg, Biochim. Biophys. Acta, 448, 589 (1976).

17) K. Weber and M. Osborn, J. Biol. Chem., 244, 4406 (1969)

18) K. Miyazaki, K. Hosoi, Y. Suzuki, Y. Nagao, Y. Matzuo and T. Horio, "Seikagaku Jikken Koza-1; Tanpakushitzu no Kagaku (Experimental Methods in Biochemistry; Protein Chemistry)," ed. by N. Ui, N. Tamiya and K. Narita, Tokyo Kagaku Dojin, Tokyo, 1976, p. 290.

19) A. H. Reisner and C. Bucholtz, Anal. Biochem., 64, 509 (1975)

20) R. M. Zacharius and T. E. Zell, ibid., 30, 148 (1969).

21) M. Dubois, K. A. Gilles, J. K. Hamilton, P. A. Rebers and F. Smith, Anal. Chem., 28, 350 (1956).

22) D. E. S. Stewart-Tull, Biochent. J., 109, 13 (1968).

23) L. Warren, J. Biol. Chem., 234, 2971 (1959).

24) I. H. Mather, K. Weber and T. W. Keenan, $J$. Dairy Sci., 60, 394 (1977).

25) G. R. Finlayson and A. Chrambach, Anal. Biochem., 40, 292 (1971).

26) R. Montgomery, "Glycoproteins," 2nd ed., ed. by A. Gottschalk, Elsevier Pub. Co., Amsterdam, London, New York, 1972, p. 518. 